\title{
ORÇAMENTO DO MUNICÍPIO MINERADOR DE PARAUAPEBAS-PA: UM PANORAMA PRELIMINAR SOBRE A AGENDA DE INVESTIMENTOS EM 2020
}

\section{Daniele Alves, Ivaneide Castro, Lidiane Felix, Luís Paulo Rodrigues, Mikaely Monteiro, Suhelen Aragão, Juliana Fernanda Monteiro de Souza, Leonardo Petrilli.}

Universidade Federal Rural da Amazônia.

DOI: 10.47094/ICONACON.2021.1

Introdução: o orçamento e as decisões de alocação dos recursos e investimentos são partes fundamentais no processo de políticas públicas, especialmente na perspectiva local e em municípios que concentram desigualdades acentuadas. De forma geral, os municípios da região norte, localizados na Amazônia brasileira, são passíveis de olhar cauteloso para as políticas públicas, dado às características e recente desenvolvimento populacional da região. Objetivo: Desta forma, o presente trabalho volta-se para o município de Parauapebas, na região sudeste do estado do Pará, com o objetivo central de observar a priorização de investimentos em um município cuja fonte prevalente de receita é a mineração. Metodologia: A pesquisa caracteriza-se como básica e descritiva, com levantamento de dados secundários junto ao portal da transparência municipal como principal procedimento de pesquisa. Os dados observados restringem-se ao terceiro bimestre do ano de 2020, período que estava disponível quando a pesquisa foi realizada. Os autores exploraram os dados obtidos tecendo uma leitura crítica. Resultados: O levantamento contempla a importância econômica da atividade minerária para o município, no qual foram arrecadados mais de $\mathrm{R} \$ 93$ milhões em tributos da atividade somente no terceiro bimestre de 2020. Uma fração significativa desta receita foi destinada para obras públicas, com mais de dez empreendimentos iniciados em menos de dois meses, entre o período de 01/05 a 30/06/2020, representando mais de R \$18 milhões do montante. Entre os serviços declarados, consta demolição de viadutos, com valor de aproximadamente R 9 milhões, e construção de ponto de moto táxi, obra com valor superior à $\mathrm{R} \$ 118$ mil, dentre outros. Outro dado que merece atenção é que no período analisado, até junho de 2020, não foram destinados recursos para saneamento básico e Parauapebas não detinha legislação e plano municipal de saneamento até dezembro de 2020. Considerações Finais: O presente trabalho apresentou, de forma preliminar, evidências de que os esforços do poder público municipal em 2020 concentrou-se em obras públicas. Os autores sugerem um aprofundamento do trabalho e o contínuo acompanhamento da matriz orçamentária do município.

Palavras-chave: Parauapebas. Amazônia. Investimento Público.

Área Temática: Administração Pública. 